\title{
Technique of performing construction works by machines with hybrid: manual and remote control
}

\author{
Nadezhda Sevryugina ${ }^{1, *}$ \\ ${ }^{1}$ Moscow state university of civil engineering, Yaroslavskoye shosse, 26, Moscow, Russia, 129337
}

\begin{abstract}
The article discusses issues dealing with efficiency of construction work mechanization. It offers a mathematical model for assessment of mutual influence between the members of the 'construction site-machine-operator' system triad, that can give a quantitative assessment of how the efficiency of a technological task varies with more comprehensive use of operational capacities of the machine, while lower effect that limiting parameters of production environment and technical condition of the machine have on the operator. The article contains a constructive remote control solution for upgrade of the base machine. It describes the conditions for using the machines with hybrid: manual and remote control at construction sites. There is also an imitation model of operator's scanning pattern and data experimental research that prove the efficiency of remotely controlled technological operations. The article proves that lower psychological load on the operator and better comfort contribute to positive economic effect and higher quality of the construction process.
\end{abstract}

\section{Introduction}

Economic stability of any country relies not only on the activity of the people, but, mainly, on the efficiency of machinery and technologies used. Progressiveness of the construction machinery development is supported by implementation of innovations obtained by scientific research of experts in many countries.

The review of developments existing has shown that the research, though systematic, is still narrow-scale. Acceleration of technical progress needs innovative updates.

Scientific foundations for managing the enhanced mechanization of construction, building the systems for remote control of the construction machinery and automatization of the construction technological processes were laid in the researches of the most prominent scientists in the sphere: P. M. Astafurov, V. I. Balovnev, N. G. Dombrovsky, A. A. Kononov, B. D. Kononykhin, M. N. Kotrovsky, Ye. M. Kudryavtsev，E. N. Kuzin, M. I. Malenkov, V. P. Pavlov, P. S. Sologub, A. N. Tarakanov, Yu. F. Ustinov and many others $[1-5,10,12,13,18]$.

Mechanization tools, in particular, construction machinery are one of the elements that affect the efficiency of the construction plan implementation. The quality of construction

\footnotetext{
${ }^{*}$ Corresponding author: SevryuginaNS@mgsu.ru
} 
works depend on technological perfection of machinery, experience of the operator and environment conditions [7, 9, 11, 14-17].

Studies of how the elements interact in the 'construction site-machine-operator' triad are still urgent for search of innovative technologies and management methods in construction. Aim of Research: theoretical-practical justification of how the construction site can make effective use of machines with hybrid: manual and remote control that increase the quality of technological operations performed.

The aim can be achieved through the solving of the following tasks:

- creating the mathematical model for the system triad 'construction site-machine-operator' adequate for comprehensive assessing the parameters of factors influence on the quality of the construction works;

- computer modelling of the operator's scanning area, when an upgraded machine with remote control performs technological operations at the construction site;

- experimental justification for the efficiency of the remote control the operator has over the construction machine;

- economic justification for expediency of construction mechanization with machines having hybrid: manual and remote control.

\section{Materials and Methods}

\section{Mathematic modelling}

Mathematic model was created after the review of the existing methods offered by best scientists in the sphere $[2,6,10,18]$.

The model suggests a hypothesis that technology operations performed at the construction sites create interconnections of element influence in the system triad "Construction sitemachine-operator" (CsMO).

Static data prove that the person is the main component of the CsMO system, and, with regard to the nature of its interaction with the other components, safety during construction operations at the site.

Each element of the system can be described by a package of characteristics presented in a certain range. For CsMO elements, functioning limits are:

$$
F_{C S M O}=\sum\left(f_{C} ; f_{M} ; f_{O}\right)
$$

Integral nature of dependence is explained by the fact that the range of system elements functioning varies with constant change of base parameters.

Function of element 'construction site' $f_{C}$, with consideration to base parameters, becomes:

$$
\begin{gathered}
f_{C}=f\left(x_{C+1}\right)=f\left(x_{C}\right)+e_{C}, \\
\int_{C_{\min }}^{C_{\max }}\left(f_{C}\right)=\int_{C_{\min }}^{C_{\max }}\left(x_{C+1}\right)=\int_{C_{\min }}^{C_{\max }}\left(f\left(x_{C}\right)+e_{C}\right),
\end{gathered}
$$

where $f\left(x_{C}\right)$ means a set of parameters characterized by physical and climatic characteristics conditions of environment; $x_{C+1}$ means quantitative changes of parameters when the whole system is in function;

$e_{C}$ means a nonnegative discrete random value that describes variability and randomness of parameters change in an element of the 'construction site' system;

$C_{\min }$; $C_{\max }$ - means limits of the 'construction site' function definition; these limits are base for any parameters of the CsMO system and their probable changes. 
The function parameters of 'Machine' and 'Operator' elements of the system are described in similar way.

With regard to the base parameters, the $f_{M}$ function of the 'machine' element becomes:

$$
\begin{gathered}
f_{M}=f\left(x_{M+1}\right)=f_{C}^{\prime}+f\left(x_{M}\right)+e_{M}, \\
\int_{M_{\min }}^{M_{\max }}\left(f_{M}\right)=\int_{M_{\min }}^{M_{\max }}\left(x_{M+1}\right)=\int_{M_{\min }}^{M_{\max }}\left(f_{C}^{\prime}+f\left(x_{M}\right)+e_{M}\right),
\end{gathered}
$$

where $f_{M}$ means a function of the machine runnability;

$f\left(x_{M}\right)$ means a set of technical and physical parameters of the machine;

$x_{M+1}$ means quantitative changes of parameters when the whole system is in function;

$e_{M}$ means a nonnegative discrete random value that describes variability and randomness of the machine functioning parameters;

$M_{\min }$; $M_{\max }$ means limits of the 'machine' function definition; they limit technical functioning of the machine and depend on current parameters of $f\left(x_{C}\right)$ and its increment.

With regard to the base parameters, the $f_{O}$ function of the 'operator' element becomes:

$$
\begin{gathered}
f_{O}=f\left(x_{O+1}\right)=f_{C}^{\prime}+f_{M}^{\prime}+f\left(x_{O}\right)+e_{O} \\
\int_{O_{\min }}^{O_{\max }}\left(f_{O}\right)=\int_{O_{\min }}^{O_{\max }}\left(x_{O+1}\right)=\int_{O_{\min }}^{O_{\max }}\left(f_{C}^{\prime}+f_{M}^{\prime}+f\left(x_{O}\right)+e_{O}\right)
\end{gathered}
$$

where $f_{O}$ means a function of the 'operator' condition;

$f\left(x_{O}\right)$ means a set of parameters that describe physical and psychological condition of the construction machine operator;

$x_{O+1}$ means quantitative changes of parameters when the whole system is in function;

$e_{O}$ means a nonnegative discrete random value that describes variations in physical and psychological condition of the construction machine operator;

$O_{\min }$; $O_{\max }$ means limits of the 'operator' function definition; they are limited by psychophysical condition, depend on current parameters of the function of the CsMO system elements and their probable changes.

The work of the construction machines operator can only be viewed in its connection with the construction site, as the influence on the latter forms a subject of the technological operation. The condition of the environment is the main factor that contributes to safe and comfortable operation of the operator and operational limitations of the construction machine.

For design reequipment of the base unit and using a remote control, the article studies the efficiency of CsMO functioning from the point of view of the remote control $\left(\mathrm{CsM}^{\mathrm{MC}} \mathrm{O}\right)$ (Fig. 1). The model $\mathrm{CsM}^{\mathrm{MC}} \mathrm{O}$ offered describes information and energy processes of the system in terms of technical and psychology interaction for some elements: 'Operator', 'Machine ${ }^{Д У '}$ ' 'object of production operation', that are placed into the 'Environment', the one of more importance, without which their objective existence is impossible. The 'environment' element is presented as a macroelement, as well as a varying border of the 'environment' local territory defined, with certain set of parameters and a border of their action. This means that production process can be managed both at the local territory, under the current conditions, and outside it.

It should be noted that the influence of parameters gives a general description for the operable state of the system. The interrelations in the CsMO system allow conclusions on 
the varying efficiency of the technological task implementation at the expense of more comprehensive use of operational capacity of the machine when the operator is exposed to varying limiting parameters that come from the environment and the machine.

To summarize, the quality of any technological operation the operator performs at the construction site $f_{O}^{\prime}$ in a designated period of time is a function of factors of environment influence $f^{\prime}$, condition of machine $f_{M}^{\prime}$ and components of operator's physical condition and professional skills:

$$
f_{O}^{\prime}=\Delta f_{C}^{\prime}+\Delta f_{M}^{\prime}+f\left(x_{O}\right)+e_{O},
$$

where we offer to treat $\Delta$ as a nonnegative variation of parameters set and their values for the appropriate function.

This mathematical model for establishing the relationship in the CsMO system affords a quantitative estimation of changing the efficiency of the technology task implementation at the expense of more comprehensive use of operational capacity of the machine when the operator is exposed to varying limiting parameters that come from the environment and the machine.

\section{Imitation Modelling}

Further research required development a computer model of the remotely controlled machine. A sample excavator was taken as a prototype for a 3D model with visualization of the construction site area the operator can scan from a work place in manual or remote control while doing technological operation of buildings disassembly. Then, we studied fields of view for bucket working position of the excavator that operates under various conditions and various positions of its track (Fig. 1).

\section{Scanning from the operator's cabin}

The quality of scanning and visibility from the operator's place in the cabin depends on the cabin position about the boom and the body of the excavator, position of the seat in the cabin, configuration of windows, quality of glass, their proper cleaning and heating, eyes protection from the direct sunlight blinding, avoiding the glaring.

Scanning patterns obtained provide more refined data for the quality of scanning from the operator's work place. For visual control of the processes that take place outside the objects of primary observation (chassis, ground under the excavator etc.) these values are very low and limit time and quality of technological operations.

\section{Scanning from a Remote Control Point}

The position of a remote control point should consider certain parameters, like distance, safety, availability, comfort etc.
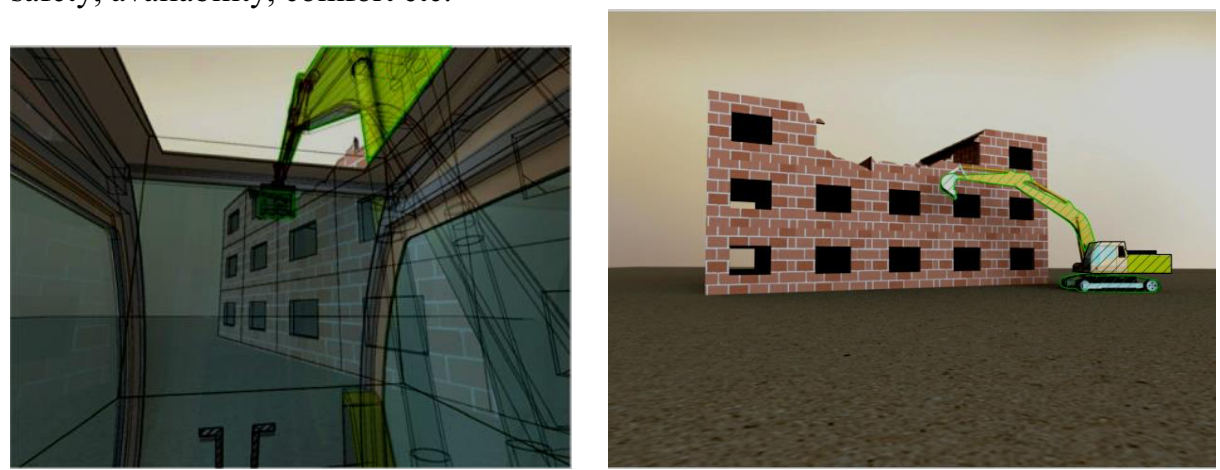

Fig. 1. Modelling the construction site space visualization for buliding disassembly: a0 manual control b) remote control. 
The scanning picture obtained for remote control demonstrates comprehensive visual control for the excavator bucket and working equipment. It was found that the operator's perception distorts the distance varying with moving away, as moving at $6.9-201.6 \mathrm{~m}$ gives 1:5.7 proportion for visual change of the excavator size.

\section{Results}

\section{Experimental research}

Experimental research was aimed at estimating the time required for performing a technological operation with a predetermined sequence for moving the elements of the excavator working equipment to preset marks (Fig. 2).
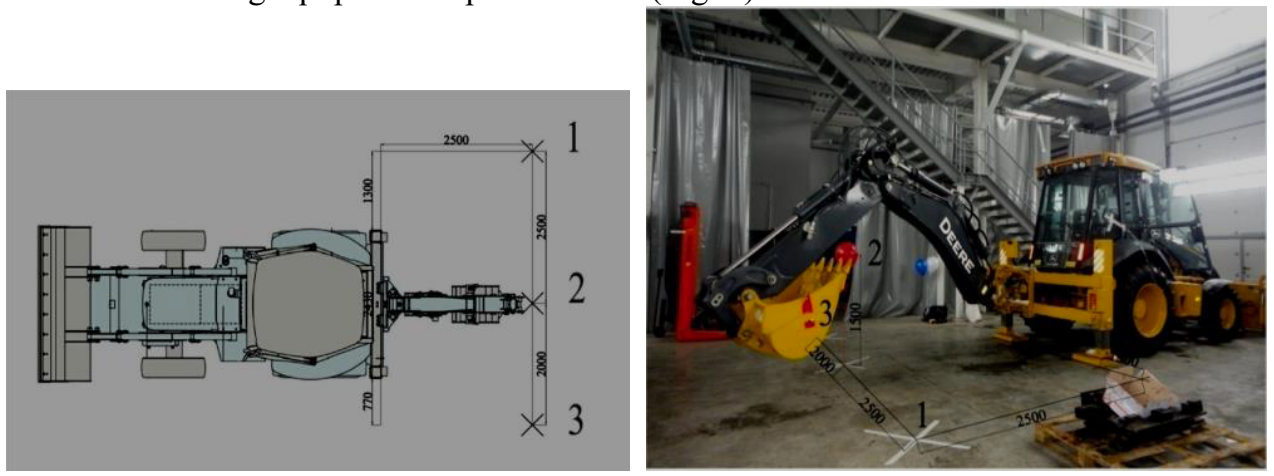

Fig. 2. Scheme of contact points

The experiment noted the following parameters:

- time the operator required for making one complete cycle that includes a sequence of touching preset points with the bucket, sec;

- vibration level at the operator's working place, Hz;

- area of visual perception from the operator's working place.

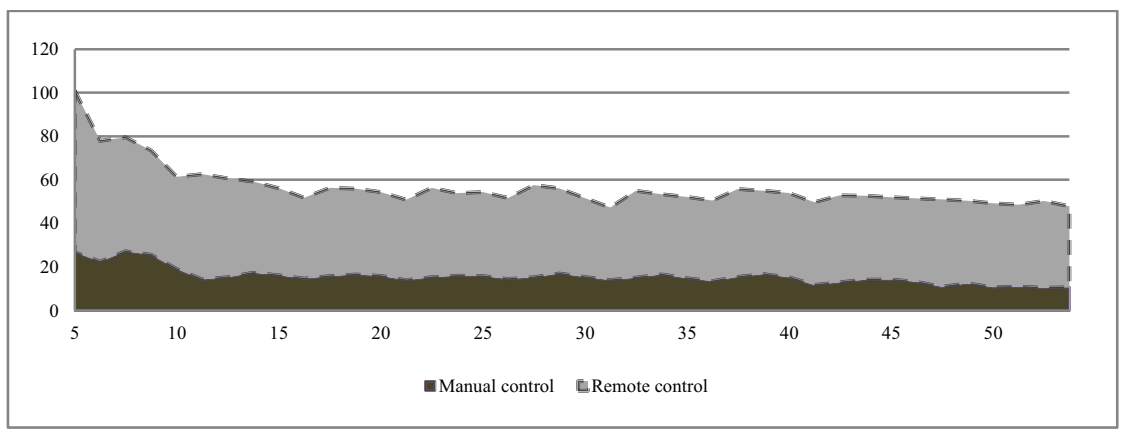

Fig. 3. Summary graph of time the operator needs for making predetermined operations in manual and remote control modes

Table 1. Extent of machine operator's visual perception of the territory involved in construction technological process

\begin{tabular}{|l|l|l|}
\hline $\begin{array}{l}\text { Position of } \\
\text { scanning } \\
\text { evaluation }\end{array}$ & Object scanning while manual control & $\begin{array}{l}\text { Object scanning while remote } \\
\text { control }\end{array}$ \\
\hline $\begin{array}{l}\text { Condition of the } \\
\text { base surface }\end{array}$ & $\begin{array}{l}\text { Scanning of object is insufficient. For better } \\
\text { view, the operator has to move his body }\end{array}$ & The objects are in full view \\
\hline
\end{tabular}




\begin{tabular}{|c|c|c|}
\hline & forward & \\
\hline Scanning of boom & $\begin{array}{l}\text { The object overlaps the field of vision at the } \\
\text { construction site. } \\
\text { The boom is in full view }\end{array}$ & $\begin{array}{l}\text { No influence to perception of } \\
\text { the construction site } \\
\text { The boom is in full view }\end{array}$ \\
\hline $\begin{array}{l}\text { Scanning of } \\
\text { handle }\end{array}$ & $\begin{array}{l}\text { The object overlaps the field of vision at the } \\
\text { construction site. } \\
\text { The handle is in limited view. }\end{array}$ & $\begin{array}{l}\text { No influence to perception of } \\
\text { the construction site. } \\
\text { The handle is in full view. }\end{array}$ \\
\hline $\begin{array}{l}\text { Scanning of } \\
\text { bucket }\end{array}$ & $\begin{array}{l}\text { The object overlaps the field of vision at the } \\
\text { construction site. } \\
\text { The bucket is in sufficient view. }\end{array}$ & $\begin{array}{l}\text { No influence to perception of } \\
\text { the construction site. } \\
\text { The bucket is in full view. }\end{array}$ \\
\hline $\begin{array}{l}\text { Information } \\
\text { display medium. } \\
\text { Interval for } \\
\text { scanning of } \\
\text { information } \\
\text { display media. }\end{array}$ & $\begin{array}{l}\text { Available for scanning. The operator has to } \\
\text { look at the control panel on his left. }\end{array}$ & $\begin{array}{l}\text { A part of information block is } \\
\text { placed at the remote control } \\
\text { panel. } \\
\text { Partial information on the } \\
\text { condition of the machine. }\end{array}$ \\
\hline $\begin{array}{l}\text { Positions } 1,2,3 \\
\text { (zones of primary } \\
\text { scanning) }\end{array}$ & $\begin{array}{l}\text { Visibility of object varies when elements of } \\
\text { working equipment gets into the operator's } \\
\text { field of view. }\end{array}$ & Fully available for scanning \\
\hline $\begin{array}{l}\text { Additional } \\
\text { comments }\end{array}$ & $\begin{array}{l}\text { Cabin stands and glazing reduce scanning, } \\
\text { as they overlap the vision and form glare. }\end{array}$ & $\begin{array}{l}\text { Changing of remote control } \\
\text { position will find the safest } \\
\text { point of control. }\end{array}$ \\
\hline
\end{tabular}

The survey of time required for the operator to make operations in manual and remote control of the excavator working equipment were processed and are shown in the graph of Fig. 3.

Experimentally, we found that the time the operator needs for making the same operations with the excavator working tool are objectively lower in case of the remote control. This is shown in the Table 1 that contains qualitative estimation for the extent of the operator's visual perception of the territory involved in the construction technology.

Switching from manual to remote control has proved the operator is psychologically ready for changing conditions of technology operations performance. The operator who had 7 years of experience needed 20-25 minutes for practicing the remote control. The control position was opposite to that of working equipment, the inversion explained by a time delay the operator had to take decision while controlling. We noted the possibility for changing the control position, body position (sitting/standing); free visual access for the main parts of the base machine to be observed; absence of vibration and other hazardous factors; higher quality of the technological task to be performed by the operator.

\section{Economic Assessment of the Results Obtained}

The reasearch proved the convergence of practical and theoretical results. Then, we had to confirm economic expediency for the remote control the machine operator performs at the construction sites.

We calculated and presented at the diagram (Fig. 4) aggegated annual operating costs for 10 working years of the machine with hybrid manual and remote control. 


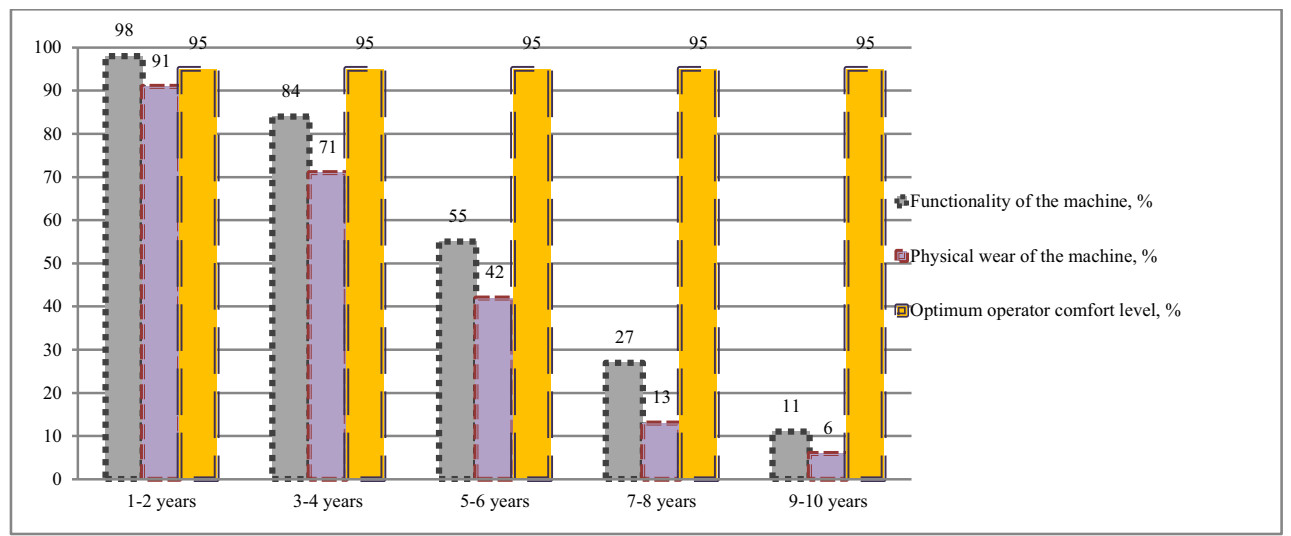

Fig. 4. Correlation of changing annual costs of a construction company that operates a remotely controlled machine

The diagram shows that the provision of operator's comfort peseet by the manufacturer gets more costly with years of operation. Physical wear of the machine manifests itself in increase of psychphysical load of the operator, the key ones being nose level and vibration in the cabin, dust content and air temperature in the cabin. The diagram shows that the remote control technology makes operator's comfort an invariant value throughout the whole period of the machine service.

\section{Discussion}

It is well known that the manufacturer procures the functionality of the machine that operator implements according to his skills and experience, that is, his psychophyical capacities and proficiency.

When the operator performs technological operatons at the construction sites, he is to disperse his attention between the factors of outer (technological operation object environment) and inner (comfortable control of the machine - stability of technical condition) perception.

Logical conclusion is that the maintenanace of the operator's comfort depends directly on the constructive perfection and and functionality of the machine, as well as on the quality of percpation of the space involved in the techonological process at the construction site. The remote control by the machine operator rreduces the effect of negative factors. Lower psychological load contributes to the feeling of security, beacuase the operator stays away from the hazards at functional zone of the machine working tool and better control over the construction object.

The methods offered is distinguished from earlier methods by the fact that its results consider for the factors of mutual influence the CsMO system elements have, thus raising the level of the machine operator's comfor to the range of constant values.

\section{Conclusions}

The article offered the solution for the task of machine remote control technology application at the technology sites that affords higher quality of the construction management.

Making the scanning pictures affords assessment of changes in the 'operator-machineconstruction site' system: security of operator and persons at the construction object, quality of the construction management and management of machine operation efficiency.

The possibility for the operator to be outside probably hazardous area while using the remote control is an effective way of creating comfortable and safe conditions of work. 
We revealed that psychophysical condition of the operator increases dynamically when he performs the remote machine control.

The comparison between the results obtained from research of technological operations performance by the construction machine operator who works in manual or remote control mode has proven the developments offered are promising.

The article has proven the economical expedience for adding remote control modules to the machines of base constructions.

\section{References}

1. R.V. Abaimov, Y.S. Bahracheva, A.V. Vasilyev, A.A. Konev, V.I. Kychkin, E. I. Lezhneva, N.S. Sevryugina, K.M. Selivanov, V.S. Yushkov, R. M. Ahmednabiev (Eds.), Road transport, Novosibirsk, 2013.

2. A.A. Bogomolov, N.S. Sevryugina, Variational interpretation of the life cycle of technical systems, Construction and road machines, (2010), No. 10, pp. 48-52. (In Russian).

3. S.N. Glagolev, N.S. Sevryugina, Efficiency of functioning of the owner-car-service system as result of the choice its accented components, Automotive industry, (2012), No. 6, pp. 10-11. (In Russian).

4. S.N. Glagolev, N.S. Sevryugina, A.A. Konev, Mathematical model of an estimation of efficiency of development of the Territory of the region with the formation of clusters of roadside service, World of transport and technological machines, (2013), No. 3(42), pp. 121-125. (In Russian).

5. O.N. Didmanidze, A.M. Karev, G.E. Mityaev, On the development prospects of road transport in the agricultural sector, International scientific journal, (2016), No. 1, pp. 5365.

6. V.A. Zorin, Bases of operability of technical systems, M.: LLC Magistr-Press, (2005), 536 p. (In Russian).

7. P.D. Kapyrin, E.S. Romanova, Analysis of current state of the building materials industry and the factors contributing to the development production, Vestnik MGSU, (2010), No. 4-1, pp. 165-170. (In Russian).

8. P.D. Kapyrin, E.S. Romanova, Modern technological line for production of threelayer wall panels, Vestnik MGSU, (2011), No. 4, pp. 490.

9. S. M. Pulyaev, M. A. Stepanov, B.A. Kaitukov, N.A. Lukyanov, N.A. Deacon, P.D. Kapyrin, Mechanical equipment and technological complexes. Textbook, Moscow: MGSU, (2015). (In Russian).

10. A.N. Novikov, O.A. Ivashchuk, V.V. Vasilieva, Ecological monitoring of the impact of transport on the acoustic environment of the city, The Repair. Recovery. Modernization, (2006). No. 6, pp. 33-34. (In Russian).

11. E.S. Romanova, P.D. Kapyrin, Modern technological lines for production of plates of overlappings, The MGSU Bulletin, (2011), No. 4, pp. 499. (In Russian).

12. N.S. Sevryugina, Modernization of building and road machines as a factor of realization of the targets, Construction and road machine us, (2007), No. 7, pp. 28-29. (In Russian).

13. N.S. Sevryugina, V.M. Babin, Resource modernization of self-propelled machines, Building and road machines, (2007), No. 9, pp. 49-53. (In Russian).

14. V.I. Telichenko, E.A. Korol', P. B. Kagan, E.N. Kulikova, Systemic administration of the trust building programs. Procing manual, Moscow: ASV, (2010). (In Russian).

15. A.D. Ishkov, N.G. Werstine, V.I. Telichenko, N.G. Miloradov, The patent for the invention. The diagnostic method of the level of claims person, RUS 2444979 from 18.08.2010. (In Russian). 
16. V.I. Telichenko, E.A. Korol', M.S. Khlistunov, S.I. Zavalishin, Global risks and new security threats responsible governmental construction projects in the metropolis, The Urban complex and the problems ispovedition of citizens, the Collection of reports of scientific-technical conference, M.: (2005), pp. 211-218. (In Russian).

17. R.R. Sharapov, A.A. Mamedov, E.V. Kharlamov, I.V. Bragin, V.V. Klochkov, Performance of illicit small self-propelled crane cargo lifting capacity of over 100 tons of improved mobility and stability, Bulletin of Belgorod state technological University. V. G. Shukhov, (2016), No. 3, pp. 112-115. (In Russian).

18. N.S. Sevryugina, S.B. Melikhova, E.A. Volkov, The solution of applied problems of optimization of stability of system "environment-man-technics", Modern Applied Science, (2015) Vol.9 No. 3, pp. 200-207. DOI: 10.5539/mas.v9n3p200 (Publisher: Canadian Center of Science and Education) 